Revista Kinesis, Santa Maria v.36, n.3, p. 115-127, set-dez. 2018

Centro de Educação Física e Desportos - UFSM

DOI: $105902 / 2316546435000$

Data de submissão: 01-10-2018

Data de Aceite: 21-11-2018

\title{
EDUCAÇÃO FÍSICA ABERTA À EXPERIÊNCIA: UM DIÁLOGO COM AS CINCO TESES DE HILDEBRANDT-STRAMANN (2009)
}

\author{
PHYSICAL EDUCATION OPEN TO THE EXPERIENCE: A DIALOGUE WITH THE FIVE THESES OF \\ HILDEBRANDT-STRAMANN (2009)
EDUCACIÓN FÍSICA ABIERTA A LA EXPERIENCIA: DIALOGO CON LAS CINCO TESIS DE HILDEBRANDT- STRAMANN (2009)

Felipe Barroso de Castro

felipecastro99@yahoo.com.br

Universidade Federal de Santa Maria - UFSM

\begin{abstract}
RESUMO
Nesse ensaio, apresento o tema da experiência relacionado ao ensino nas aulas de Educação Física sob a perspectiva do "se-movimentar". Para isso proponho um diálogo com as cinco teses de Hildebrandt-Stramann (2009) para uma Educação Física aberta à experiência. Acredito que as teses propostas pelo autor apontam para a importância e a necessidade de exploração de experiências corporais na escola frente a um aparente "empobrecimento" do mundo de movimentos de crianças, consequência de fatores como a exposição precoce, sem o devido cuidado, as novas tecnologias o que, por vezes, as afasta do brincar e das experiências sensíveis.
\end{abstract}

Palavras-Chave: Educação Física; Experiência; Se-movimentar

\section{ABSTRACT}

In this essay, i present the theme of experience related to teaching in Physical Education classes from the perspective of "se-movimentar". For this i propose a dialogue with the five theses of Hildebrandt-Stramann (2009) for a Physical Education open to the experience. I believe that the theses proposed by the author point to the importance and necessity of exploring body experiences at school in the face of an apparent "impoverishment" of the world of children's movements, consequence of factors such as early exposure, without due care, to new technologies, which sometimes depart them from play and sensitive experiences.

Keywords: Physical Education; Experience; Se-movimentar

\section{RESUMEN}

En este artículo presento el tema de la experiencia relacionado a la enseñanza en las clases de educación física bajo la perspectiva del "se-movimentar". Para tanto, propongo un dialogo con las cinco tesis de HildebrandtStramann (2009) para una educación física abierta a la experiencia. Creo que las tesis propuestas por el autor apuntan hacia la importancia y necesidad de explorar experiencias corporales en la escuela frente a un aparente “empobrecimiento” delmundo demovimientos deniños, comoconsecuencia defactoresa ejemplo dela exposición precoz, sin debido cuidado, a las nuevas tecnologías que por veces aleja del jugar y de las experiencias sensibles.

Palabras Clave: Educación Física; Experiencia; Se-movimentar 


\section{Introdução}

A Concepção das Aulas abertas (ou Ensino aberto) criada pelos professores alemães Reiner Hildebrandt-Stramann e Ralf Laging (1986) foi de grande influência para o período e para um novo momento da Educação Física brasileira. A mudança de paradigmas em relação ao movimento humano, a cultura de movimento, ao ensino e também a legitimidade da Educação Física na escola fizeram com que essa concepção fosse ganhando espaço nas universidades e nas escolas. A partir desse trabalho, novos debates e reflexões foram propostos pelo Grupo de trabalho pedagógico UFPE/UFSM (1991) e pelo próprio professor Hildebrandt-Stramann no Brasil como nos conta a resenha de Oliveira (2005).

O tema da experiência ocupa centralidade na Concepção das Aulas abertas, sendo considerada uma categoria preponderante e que foi retomada por Hildebrandt-Stramann em vários de seus estudos subsequentes (2001, 2009, 2018). Um deles, em especial, intitulado "Educação Física aberta à experiência: uma concepção didática em discussão" publicado em 2009 traz aprofundamentos teóricos e discussões interessantes sobre diversos temas em que a categoria experiência se faz presente. Assim, o movimentarse, o processo de ensino-aprendizagem por oficinas, o aprender diante de problemas, a "escola móvel" e a formação de professores são alguns dos assuntos tratados no livro e que trouxeram grandes contribuições didáticas e pedagógicas para uma Educação Física crítica e responsável como aponta o próprio autor ${ }^{1}$.

Essa obra já foi resenhada por Batalha-Lemke (2008) que apresentou a proposta do livro situando-o como oportuno frente a necessidade de se olhar para a realidade da vida cotidiana como uma relação ser humano e mundo. Como introduz a autora, "a obra de Hildebrandt-Stramann surge como uma alternativa de se pensar e, de se fazer atuar nesta sociedade que se 'revela' em dois mundos: o 'mundo virtual' e, o 'mundo-vivido"” (BATALHA-LEMKE, 2008, p. 257).

As análises de Hildebrandt-Stramann (2009) situam o movimento humano na perspectiva de um "se-movimentar", ou seja, entende o movimento como diálogo entre ser humano e mundo, dotado de intencionalidade e que, fundamentalmente, precisa levar em consideração o ser humano que se movimenta (os alunos). Daí sua preocupação em valorizar o mundo vivido de crianças e jovens na escola.

Embora o tema da experiência esteja presente ao longo dos 8 capítulos de sua referida obra, é no $2^{\circ}$ capítulo (Experiência: uma categoria central na aprendizagem do movimentar-se), que o autor apresenta cinco teses objetivas em relação a experiência enquanto uma categoria relevante para os processos de ensino. É nesse momento que Hildebrandt-Stramann (2009) especifica seu conceito de experiência e experiência corporal e apresenta princípios didáticos para a efetivação do ensino nessa perspectiva.

1 O livro conta ainda, em alguns capítulos, com a contribuição dos professores Heike Beckmann, Klaus Wichmann, Vera Luza Uchôa Lins e Amauri Bássoli Oliveira. 
Na resenha de Batalha-Lemke (2008), as teses desse capítulo são descritas brevemente apresentando o conteúdo central de cada uma. Não há, portanto, uma discussão ou problematização desses tópicos onde acredito que esteja a proposição mais clara colocada por Hildebrandt-Stramann (2009) para uma Educação Física aberta à experiência. O conjunto dessas teses pode nos apresentar relevantes contribuições para a efetivação prática de uma proposta didática de Educação Física que se preocupa, entre outras coisas, com maneiras de se-movimentar e não propriamente com formas de movimento.

Em uma sociedade onde as experiências sensíveis têm dado espaço para vivências, ou seja, formas fragmentadas de apreensão da realidade (BENJAMIN, 1987, 1989)² e a escola parece contribuir para um controle demasiado da criança, o que inclui suas possibilidades de experiências (CASTRO; KUNZ, 2015); a Educação Física deve assumir o papel de um espaço/tempo que possibilite um reencontro com experiências cinestésicas. Isso implica valorizar momentos de aprendizagem pelo vivido e experienciado, cada vez mais raro frente a um mundo de informações tão (des) conectado a tudo e ao mesmo tempo a nada.

\section{Se-movimentar: um reencontro com experiências corporais sensíveis}

Segundo Hildebrandt-Stramann (2009), a noção de experiência que aparece ligada ao movimento humano, especialmente nas aulas de Educação Física, está, indubitavelmente, relacionada ao corpo; e por isso precisamos compreendê-la como uma experiência corporal. Essa noção de experiência considera a dimensão da sensibilidade humana como primordial. Hildebrandt-Stramann (2009, p. 26) exemplifica:

A experiência de espaço e tempo, as duas dimensões básicas nessa aprendizagem, fundamentalmente ligadas ao corpo, são qualidades não acessíveis a uma instrução direta. Não se pode ensiná-las, assim como não se ensina a ter sensibilidade com bola, a ter equilíbrio ou ritmo. Tais experiências, porém, são transmissíveis na Educação Física através de arranjos, situações e condições que possibilitam e promovem capacidades, estratégias e habilidades.

Isso implica, como apontam Almeida, Fensterseifere Bracht(2014), compreendermos a experiência como uma dimensão a ser induzida, mas não conduzida nas aulas de Educação Física. O professor pode induzir os alunos a realizarem experiências, configurando o espaço de ensino, usando de estratégias em determinadas situações para que haja essa 2 Walter Benjamin $(1987,1989)$ apropriou-se de temas como a técnica, a vivência, a estetização, a sensação, o trabalho, a memória, a imaginação, entre outros para discutir o tema central da experiência e sua degradação no período moderno. No entendimento de Jay (2009), essas reflexões circunscreveram a base de um método crítico benjaminiano sobre experiência. 
possibilidade, sem, no entanto, deter total controle sobre as ações subsequentes, as quais dependem muito mais dos próprios alunos. Vale destacar, portanto, que a dimensão da experiência precisa ser entendida como espaço de participação e abertura; e jamais como manipulação e controle (ALMEIDA; FENSTERSEITER, 2011).

Como alerta Hildebrandt-Stramann (2009), devemos ter o cuidado em considerar que nem toda forma de movimento leva a experiência. O movimento técnico esportivo, por exemplo, aparece na forma de padrões de movimento, o que pode dificultar a exploração de novas possibilidades desse se-movimentar. Isso porque, no esporte, "as técnicas se impuseram como soluções ótimas para os problemas de movimento" (HILDEBRANDTSTRAMANN, 2009, p. 26) e a sua transmissão irrefletida nas aulas de Educação Física não explora outras possibilidades além das já estipuladas para esse se-movimentar padronizado. Como destaca Maraun (2006), a reprodução desses movimentos apenas reafirma padrões criados e cientificamente comprovados pela experiência de outros, mas não do aluno, por exemplo.

A experiência encontra possibilidades no movimento quando temos a noção desse movimento enquanto um se-movimentar (HILDEBRANDT-STRAMANN, 2001, 2009; KUNZ, 2012). Essa concepção de movimento parte de uma compreensão integral de homem, mundo e movimento. Logo, o movimento é tratado como “diálogo" entre homem e mundo, como expressão de sentidos e significados que se delineiam a partir do semovimentar. Esse diálogo, segundo Trebels (2006, p. 40 e 41), acontece na forma de um jogo de perguntas e respostas, pois

[...] na ação de movimento o mundo e as coisas, no seu ser/estar, são questionados pelo sujeito/ator do movimento. Enquanto isso, o movimento próprio do sujeito ajustase aos objetos encontrados e intencionalmente questionados, ou seja, ele também oferece uma resposta ao 'ser-assim-do-mundo'.

A concepção do se-movimentar, segundo Hildebrandt-Stramann (2001), surge de uma visão fenomenológica do movimento. Nessa visão, o movimento não pertence, exclusivamente, nem ao homem e nem ao mundo, mas sim ao relacionamento estabelecido entre ambos. Por essas considerações, a visão fenomenológica caracteriza-se como uma visão pedagógica, pois valoriza os alunos que se movimentam e a situação em que esse movimento acontece (HILDEBRANDT-STRAMANN, 2001).

Para Hildebrandt-Stramann (2001, 2009) e Kunz (2012) não somete o movimento deve ser concebido enquanto diálogo, mas também o próprio ensino da Educação Física na escola também deve se desenvolver de maneira dialógica. A dialogicidade, segundo os autores, é uma dimensão que está, indubitavelmente, presente em nossas vidas. Na comunicação verbal, nos gestos, no movimento, no processo educativo, enfim, nas relações humanas; o diálogo é determinante para a consideração e valorização da sensibilidade como uma dimensão humanizadora. 
Da relação dialógica entre professor e aluno surgem inúmeras possibilidades de aprendizagem, mas que nem por isso irão se traduzir em aprendizagens passíveis de controle por esses dois sujeitos. Hildebrandt-Stramann (2009, p. 14) explica:

Se o aluno se esforçar, enfim, é sua decisão, não tomada independentemente dos esforços do professor, mas também não totalmente dependente disso. Nesse caso, portanto, a ideia de que alguém seja educado por outro - pelo professor - é um engano. O educador não pode dispor da ação de alguém, isto é, não é possível transformar a intenção do professor em ação do aluno. Uma avaliação errônea do ato educativo pode levar o educador tanto a resignar-se com o resultado obtido quanto a tomar medidas mais rigorosas no seu desempenho didático-pedagógico.

Um ensino dialógico e também problematizador está preocupado em criar espaços e possibilidades para que se possa solucionar/resolver problemas pela experiência a partir do processo de "ação-reflexão-ação" (KUNZ, 2012). Isso porque essa concepção de ensino considera os sujeitos que se movimentam na busca pelo "agir autônomo" em confronto com problemas. Autonomia e competência são duas características que vão consolidandose a partir do ensino baseado pela resolução de problemas, mas que também induzem os alunos a questionarem novas situações, inclusive, as próprias soluções encontradas.

Frente ao cenário ainda presente na escola, onde o ensino técnico diretivo vigora no sistema educacional, muitos são os entraves para a efetivação de um ensino dialógico e uma abertura para experiências nesse processo. A situação ainda é potencializada, como apontou recentemente Hildebrandt-Stramann (2018), pela própria organização escolar em que há um tempo e um lugar para pensar, refletir, raciocinar de maneira imóvel (sala de aula); e um tempo e um lugar para o agir (Educação Física).

Nas palavras de Hildebrandt-Stramann (2018, p. 4)

[...] a Escola também percebe que os alunos não podem exercitar apenas a 'cabeça' com as modalidades de raciocínio lógico das disciplinas mais 'nobres', como a matemática, ciências, entre outras, e então concede ao 'restante do corpo' um tempo. O corpo é, por assim dizer, duplamente disciplinado: de um lado ele não deve se mexer na aula, de outro lado, só pode se mexer em tempos e espaços predeterminados, o que muitos estudantes interiorizaram rapidamente.

Na visão do autor, não deveria haver na escola uma separação tão drástica entre o "pensar" e o "agir", assim como para a própria materialização de proposições pedagógicas que se preocupam como um ensino dialógico e problematizador. Para Hildebrandt-Stramann (2018, p. 3), considerando que em teoria o pensar e o agir estão relacionados, "então está certo dizer que agir sem pensar é cego, e que pensar sem agir é vazio, e portanto a questão que se coloca é se o pensar fun $c$ ciona como um todo, se não considerarmos o agir? Não deve cada teoria se basear numa prática?". 
Penso que para uma Educação Física responsável e ciente de seu papel educacional e formativo na escola, a categoria da experiência enquanto possibilidade de exploração do se-movimentar pode trazer grandes contribuições pedagógicas. Trata-se de valorizar aqui o tempo e o espaço que a Educação Física tem para proporcionar experiências significativas de movimento, mas também de discussão e reflexão sobre elementos que compõe o mundo de movimentos de nossos alunos.

Acredito que as teses propostas por Hildebrandt-Stramann (2009) são indicativos que apontam não somente a importância, mas também a necessidade de exploração de experiências corporais frente a um cenário escolar, por vezes, desestimulante em um mundo que nossos alunos têm encontrado maiores possibilidades de realização, prazer e "conhecimento" dentro de celulares e menos pelo convívio social e pelas práticas corporais. Na sequência apresento essas teses propondo análises e discussões sobre cada uma delas.

\section{$1^{\mathrm{a}}$ Tese: o movimento orientado na experiência é autêntico.}

[...] Devem existir situações de movimento e experiência para a solução e domínio de problemas nessa área, do ponto de vista do aprendiz. As ações devem referir-se unicamente a esses aprendizes, pois somente assim podem levar a um sentido. Os resultados têm que ser atributos subjetivos, pois só então se desenvolvem conceitos de autoeficácia (HILDEBRANDT-STRAMANN, 2009, p. 27).

O movimento orientado na experiência é autêntico porque é resultado de intenções de movimento dos alunos. São expressões subjetivas do se-movimentar e, por isso, mantém relação direta com quem as produz. Os movimentos surgem de maneira inventiva e criativa, voltados para a resolução de problemas em determinadas situações de movimento, uma vez que pela prática, os alunos procuram motivos de movimento.

A reprodução de movimentos técnicos, padronizados e esteriotipados, próprios do ensino normatizado e tradicional dos esportes, é substituída por outro tipo de reprodução de movimentos. Aceita-se, nessa perspectiva, a reprodução de movimentos autênticos que são dotados de sentidos e significados pelos sujeitos dessa experiência. Não significa negar, portanto, o valor do exercício e da repetição para o aprendizado de movimentos mais complexos e que possam exigir aprimoramento, desde que os próprios alunos possam ser os sujeitos dessa experimentação e, consequentemente, dessa descoberta.

Nesse ponto, como destaca Kunz (2012, p. 210), há a possibilidade de se valorizar o aprendizado pela imitação de movimentos. No entanto, esclarece o autor, "o aprender não consiste jamais pela ‘imitação da forma', [... ] mas um movimento deve ser aprendido por uma estratégia, que Tamboer denominou de “imitação de uma intenção”'. Significa que há uma centralidade da representação intencional do movimento, ou seja, temse no movimento uma "intenção em fazer", a qual corresponde a uma resposta para 
determinado objetivo (KUNZ, 2012).

Não se afirma, descreve Trebels (2006), a existência de um movimento ideal, mas sim de maneiras de se-movimentar que, pelo confronto e diálogo com a situação, vão delineando valores alcançados pela sensibilidade corporal. Quando realizamos um movimento, pela experiência, apresentamos, ao mesmo tempo, "um sentimento de valoração da ação, uma espécie de aceitação do que é correto e negação do que é incorreto” (TREBELS, 2006, p. 29).

Quando a experiência de movimentos do mundo vivido é desconsiderada e as estratégias de ação racionalistas são supervalorizadas, o que acontece muitas vezes nas aulas de Educação Física, como destaca Hildebrandt-Stramann (2001); perdemos o vínculo com esse se-movimentar autêntico. Essa perda resulta em aprender a perceber e sentir cada vez mais o que existe para ser percebido e sentido, conforme a realidade técnica e física.

\section{$2^{\mathrm{a}}$ Tese: o movimento com base na experiência tem caráter de diálogo.}

[...] O movimento recebe seu estímulo e seu interesse: isso faz com que aquele que se movimenta se comunique com seu meio ambiente material e social. O movimento com a percepção é a união da ação sobre o mundo e a reação sobre si mesmo, de impressão e expressão, de momentos produtivos e explorativos, e encontra-se na polaridade entre a chance de ganhar e o risco de perder (HILDEBRANDT-STRAMANN, 2009, p. 27).

O movimento com base na experiência tem caráter de diálogo porque, ao nos movimentarmos, estabelecemos relações com o mundo, como já mencionado anteriormente em Trebels (2006). Movimentar-se é uma forma espontânea de compreender o mundo pela ação. Somos sujeitos que se movimentam. Não estamos, por isso, separados do movimento, mas estamos com ele, nos expressamos intencionalmente ao nos movimentarmos.

Diariamente, recebemos estímulos e respondemos a eles de uma maneira que nos é própria. Pelo se-movimentar, os alunos respondem a problemas de movimento e aí está o papel fundamental que as "situações de movimento" podem propiciar. Elas aparecem para os alunos em uma multiplicidade de elementos, exigindo a elaboração de soluções e respostas.

Maraun (2006, p. 196), ao citar o exemplo do jogo de tênis e afirmar que "o jogar tênis não pode ser aprendido"” , destaca que quem ensina, verdadeiramente, é a situação, já que o professor apenas realiza a mediação. Em alguns momentos, segundo ela, o professor pode preparar a situação para uma aprendizagem, já que, por vezes, “é possível desenvolver, com muito mais facilidade, uma organização mais significativa de movimentos. O professor economiza, assim, um tempo precioso na correção de 3 Ver Maraun (2006, p. 196 e 197). A autora especifica em detalhes o exemplo de jogar tênis. 
movimentos e ensina [...] a 'pensar por dentro dos acontecimentos"' (MARAUN, 2006, p. 197).

Trata-se de possibilitar situações de aprendizado que colaborem para a autonomia dos alunos, para um autoconhecimento, para um ensino em que o professor cumpre o seu importante papel de mediador e facilitador, mas que, fundamentalmente, é o aluno o protagonista desse aprendizado.

\section{$3^{\mathrm{a}}$ Tese: as experiências são reações da ação efetiva.}

Somente pela ação efetiva as experiências se tornam próprias e são incorporadas, convertendo-se em possível apoio ao indivíduo no futuro. A experiência une o novo com o antigo, o passado com o presente e o futuro; ela é a articulação entre as capacidades de ação passada, presente e futura (HILDEBRANDT-STRAMANN, 2009, p. 28).

As experiências são reações da ação efetiva porque só se materializam quando as intenções do sujeito que se movimenta estão voltadas para um interesse sobre a própria realização de experiências. Isso significa que, havendo condições objetivas para a experiência, o sujeito a aceita; ele se insere e a explora das mais diversas maneiras. No entanto, nessa exploração assume-se também o risco do erro ou do equívoco, que são ao mesmo tempo que características "negativas", também possíveis consequências do que realmente é se expor a fazer experiências (LARROSA, 2002).

Hildebrandt-Stramann (2009) deixa claro, nesse ponto, que a experiência não é uma fase lúdica que antecede sempre uma aprendizagem correta, assim como também não é um experimentar descompromissado, mas sim um comprometimento com tarefas de movimento, com um fazer pedagogicamente produtivo. Trata-se de considerar que a experiência, portanto, está menos para a esfera da exatidão do acerto e do êxito, e mais para a esfera da imprevisibilidade. Portanto, aprender pela experiência, em um sentido temporal, exige e considera a união de experiências positivas e negativas com o material, com o vivido, o que exige tempo e continuidade.

\section{$4^{\mathrm{a}}$ Tese: o objeto da experiência é a incorporação do novo e do desconhecido.}

Uma experiência se faz quando alguma coisa se contraria em relação a algo conhecido e habitual, quando alguma coisa é desviada do rotineiro. Através de acontecimentos que permanecem nos moldes dos esquemas habituais, não se podem fazer experiências; apenas, quando muito, experiências já feitas podem ser confirmadas, diferenciadas e consolidadas (HILDEBRANDT-STRAMANN, 2009, p. 28 e 29).

O objeto da experiência é a incorporação do novo e do desconhecido porque, em 
sua autenticidade, ela precisa realizar-se em meio a imprevisibilidade das situações vividas. Da relação entre a solução de problemas e a descoberta, os alunos podem incorporar o novo ao seu "mundo de significados motores" (KUNZ, 2012). Estando a incerteza presente nesse processo, os resultados alcançados pelo movimento apresentam não somente chances de sucesso, mas também de fracasso, como descrevi anteriormente, uma vez que podem contrariar expectativas.

À experiência que atende nossas expectativas e as confirma, damos o nome de experimento como trata Larrosa (2002). A experiência no movimento não está presente na simples constatação de algo, tampouco, como destaca Hildebrandt-Stramann (2009), na rotina de ações habituais e cotidianas. O exercício e a reflexão sobre as experiências vividas em aula apresentam o que Larrosa (2002) descreveu como a atribuição do sentido ou do "sem-sentido" em relação ao vivido. Desse processo, surge o saber da experiência. Um saber que, nas aulas de Educação Física em que o movimento está orientado na experiência, aparece pelo se-movimentar, mas também pelo "saber sobre esse semovimentar".

Como argumentam Almeida e Fensterseifer (2011, p. 251), o discurso sobre a cultura de movimento, ou o que estamos tratando aqui como o se-movimentar, se realiza apenas no plano conceitual, ou seja, "não nos permite uma interpretação a partir da experiência, das vivências de movimento/práticas corporais, mas pela sua descrição”. A dimensão da experiência e do saber da experiência surgem, então, como possibilidades para que possamos "conhecer, fazer e conhecer esse fazer" durante as aulas.

\section{$5^{\text {a }}$ Tese: as experiências estão baseadas em auto-esboços projetivos.}

Trata-se de transcender, direta e autonomamente, as competências atuais de ação. Habitualmente isso se dá, de início, num esboço mental, por mais rudimentar que seja. [...] Eles são, antes de tudo, projeções de si mesmo, da pessoa na sua integridade; são projeções para o interior de um espaço desconhecido e, com isso, em parte, projeções na incerteza. Tais projeções referentes ao futuro são sempre autoesboços que transcendem à própria pessoa e às competências atuais de ação (HILDEBRANDTSTRAMANN, 2009, p. 28 e 29).

As experiências estão baseadas em auto-esboços projetivos porque, ao agir, o sujeito apresenta para si mesmo uma breve projeção ante o movimento, ou seja, uma idealização prévia que antecipa o movimento propriamente dito. O ato de transcender, como argumenta Kunz (2012), envolve o sujeito deste acontecimento sempre na sua intencionalidade. Nesse caso, a intencionalidade se estabelece pela ideia ou imagem de movimento a partir de auto-esboços projetivos. Nas palavras do autor, "é por meio desta intencionalidade que se constitui o sentido/significado do se-movimentar. Sentido/ significado e intencionalidade têm, assim, uma relação muito estreita" (KUNZ, 2012, p. 
209).

A noção de projeção apenas nos instiga a pensar que os alunos "se imaginam" no movimento. A ação de projetarem-se no movimento foge ao controle daquilo que pode ser explicado e descrito literalmente. Logo, as projeções também são permeadas pela incerteza. $O$ esboço da ação, a execução e a experiência formam juntos uma unidade indissociável e inseparável.

As cinco teses propostas por Hildebrandt-Stramann (2009) demonstram que existem dimensões presentes no ensino aberto às experiências que fogem do controle do professor assim como de um rigoroso apanhado metodológico de ensino, próprio do ensino estritamente diretivo. A incorporação do novo, do desconhecido, a autenticidade de maneiras de se-movimentar, o exercício de imitação de intenções de movimento são exemplos de elementos em que o professor auxilia os alunos, criando espaços e situações para essa ocorrência, mas sem poder controlar totalmente a repercussão desses aprendizados e formas de aprendizado para os alunos.

Para a efetivação desse conjunto de ideias, os espaços de intervenção precisam ser configurados a partir dos objetivos que, como professores, pretendemos alcançar. No entanto, como afirma Kunz (2012), essa tarefa não é nada fácil frente a dependência que um ensino aberto às experiências tem com a abertura da própria escola. Esse fator pode nos impor condições objetivas que embora influenciem, não necessariamente determinam nossa atuação como professores. Por isso, mesmo que tenhamos consciência do quanto ideias, concepções e propostas diferentes das já enraizadas defrontam-se com obstáculos de efetivação e aceitação na escola (ou em algumas escolas), nossa atuação pode encontrar nos chamados “espaços vazios" - expressão que Kunz (2012) toma emprestada de Paulo Freire - possibilidades e alternativas de mudanças.

Espaços vazios são "brechas", "lacunas" existentes no modelo de organização escolar pelas quais o professor pode encontrar alternativas para desenvolver novas ideias e perspectivas. Sem dúvida também, a colaboração dos alunos é fator determinante, a qual pode otimizar ainda mais as possíveis mudanças a partir desses espaços vazios. Uma vez que se a proposta é a de um ensino aberto e centrado nas experiências corporais desses sujeitos, obviamente que estes serão os protagonistas do sucesso ou do insucesso dessa mesma proposta. Notadamente, essa conscientização e valorização dos alunos parte inicialmente e constantemente do professor e é um processo configurado por ele, o que sem dúvida, é demorado e trabalhoso.

\section{Considerações Finais}

O culto ao esporte normativo e a valorização do deus movimentos técnicos na escola tem colaborado para pobreza de experiências corporais subjetivas e sensíveis que pudessem explorar outras maneiras de se-movimentar, o que não é novidade nos 
estudos da Educação Física, mas ainda se faz presente na realidade escolar. No entanto, outro fator incômodo tem aparecido, qual seja o também empobrecimento do mundo de movimentos de crianças na escola.

As crianças não chegam à escola "esvaziadas" de experiências corporais, ou seja, elas apresentam, mesmo que minimamente, um repertório de movimentos no seu semovimentar. O que chama a atenção é a pobreza desse repertório, consequência dos novos tempos, onde poucas crianças ainda brincam na rua, se relacionam com outras crianças, tem contato com a natureza (terra, árvore, animais). Não fosse o bastante, o contato precoce dessas mesmas crianças, sem o devido cuidado, com as tecnologias por meio dos celulares, videogames e tablets tem demonstrado que este parece ser um mundo atraente para elas e que, ao mesmo tempo, as afasta do brincar que na perspectiva de um se-movimentar deveria ser uma ação natural do ser humano.

Não quero aqui fazer generalizações, pois é claro que o momento da Educação Física mantém o seu prestígio com crianças. É o momento de correr, rir, se relacionar e isso ainda está evidente. A questão que se coloca está sobre o mundo de movimentos dessas crianças, possibilidades de se-movimentar, conhecimento sobre movimentos; o que ao meu ver parece sofrer influências desses novos tempos. Frente a esse cenário, nossa tarefa como professores de Educação Física não é nada simples. Uma Educação Física aberta às experiências aparece como uma alternativa necessária para o enriquecimento cultural, social e, fundamentalmente, do mundo de movimentos de crianças e jovens.

Na escola, alunos que são estimulados a se-movimentar de forma exploratória e criativa o fazem pelas suas intenções de movimento. A experiência presente no semovimentar realiza-se em uma dimensão sensível, ou seja, está relacionada ao "sentir" e, portanto, o "fazer experiência” valoriza sempre dimensões sensíveis/subjetivas. Isso implicaria, inclusive, afirmar que a importância da experiência no movimento pode estar, justamente, na busca pela recuperação de características sensíveis humanas, como a criatividade e a curiosidade, que, aparentemente, são deixadas de lado no ensino institucionalizado da escola. Incentivar esses momentos, portanto, é possibilitar arranjos e situações que possam ser experienciados pelos alunos, uma vez que não podemos ensiná-los objetivamente.

A valorização do mundo vivido de nossos alunos também pode aparecer como um universo a ser explorado dentro da escola. Na realidade, a escola e a Educação Física parecem funcionar, muitas vezes, como uma "rede de polimento" dessas experiências, quando, pelo contrário, deveriam reconhecer esse mundo, trazendo esses elementos também para o espaço escolar. Isso significa considerar as experiências do mundo vivido desses alunos não pela simples aceitação e reprodução, o que levaria a uma prática espontaneísta, mas como um desafio às intencionalidades da escola como instituição formal de ensino em construir espaços e sentidos educativos para e com esses elementos.

As cinco teses de Hildebrandt-Stramann (2009) trazem grandes contribuições 
porque sistematizam ideias centrais que precisam ser consideradas para uma efetivação dessa proposta. Trata-se de um resumo sobre um tema complexo e que não é de fácil abordagem na escola. A perspectiva de um ensino aberto, de exploração de materiais e de espaços alternativos dentro da escola pode não agradar instituições que zelam pelo controle de tudo e todos. O trabalho com a perspectiva da experiência no se-movimentar, portanto, exige paciência e continuidade para que os frutos dessa prática possam aparecer e demostrar, de algum modo, o valor pedagógico, educativo e formador para a vida dos alunos e também para a escola enquanto espaço educativo.

\section{Referências}

ALMEIDA, Luciano; FENSTERSEIFER, Paulo E. O lugar da experiência no âmbito da Educação Física. Movimento, Porto Alegre, v. 17, n. 04, p. 247-263, out./dez., 2011.

ALMEIDA, Luciano.; FENSTERSEIFER, Paulo E.; BRACHT, Valter. Experiência. In: GONZÁLEZ, Fernando J.; FENSTERSEIFER, Paulo E. Dicionário Crítico de Educação Física. 3. ed. ljuí: Unijuí, 2014. p. 297-302.

BATALHA-LEMKE, Jozilma. Educação Física aberta à experiência - uma concepção didática em discussão. Reiner Hildebrandt-Stramann [Rio de Janeiro: Imperial Novo Milênio, 2009]. Motrivivência, Florianópolis, Ano XX, n. 31, p. 256-273, dez., 2008.

BENJAMIN, Walter. Magia e Técnica, Arte e Política. 3. ed. São Paulo: Brasiliense, 1987.

. Charles Baudelaire: um lírico no auge do capitalismo. São Paulo: Brasiliense, 1989.

CASTRO, Felipe B.; KUNZ, Elenor. O fazer experiência do ser-criança: entre o estímulo e a descoberta. In: KUNZ, Elenor (Org.). Brincar \& Se-movimentar: tempos e espaços de vida da criança. Ijuí: Unijuí, 2015. p. 117-129.

GRUPO DE TRABALHO PEDAGÓGICO UFPE/UFSM. Visão didática da Educação Física: análises críticas e exemplos práticos de aulas. Rio de Janeiro: Ao Livro Técnico, 1991.

HILDEBRANDT, Reiner; LAGING, Ralf. Concepções abertas no ensino da educação física. Rio de Janeiro: Ao livro técnico, 1986.

HILDEBRANDT-STRAMANN, Reiner. Textos pedagógicos sobre o ensino da educação física. ljuí: Unijuí, 2001. 
. Educação física aberta à experiência: uma concepção didática em discussão. Rio de Janeiro: Imperial Novo Milênio, 2009.

. "Pensar e Agir" como princípio didático fundamental e básico para um processo de aprendizagem escolar. Kinesis, Santa Maria, v. 36, n. 2, p. 02-10, mai./ago., 2018.

JAY, Martin. Cantos de Experiencia: variaciones modernas sobre un tema universal. Buenos Aires: Paidós, 2009.

KUNZ, Elenor. Educação Física: Ensino \& Mudanças. 3. ed. ljuí: Unijuí, 2012.

LARROSA, Jorge. Notas sobre a experiência e o saber da experiência. Revista Brasileira de Educação, São Paulo, n. 19, p. 20-28, jan./abr., 2002.

MARAUN, Heide-Karen. Ensino-aprendizagem aberto às experiências. Sobre a gênese e estrutura da aprendizagem autodeterminada na educação física. In: KUNZ, Elenor.; TREBELS, Andreas H. (Orgs.). Educação Física Crítico Emancipatória. Com uma perspectiva da pedagogia alemã do esporte. ljuí: Unijuí, 2006. p. 177-202.

OLIVEIRA, Amauri A. B. Textos Pedagógicos Sobre o Ensino da Educação Física. Movimento. Porto Alegre, v. 11, n. 1, p.171-182, jan./abr., 2005.

TREBELS, Andreas H. A Concepção Dialógica do Movimento Humano. Uma Teoria do "Se-Movimentar". In: KUNZ, Elenor.; TREBELS, Andreas H. Educação Física Crítico Emancipatória. Com uma perspectiva da pedagogia alemã do esporte. ljuí: Unijuí, 2006. p. 23-48. 